\title{
A Child Multilingualism Need at Elementary Level Education: From Parents' Perspective: Using Domains Theory Approach (A Case of Saaho-Speaking Parents in Senafe Sub-region, Eritrea)
}

\author{
Omer Suleiman Idris \\ Master Candidate. Northeast Normal University, China
}

\begin{abstract}
Language need assessment in education is indispensable before step up to language policy panning and formulation, and been said certainly true in decisions concerning the languages of education, and yet the attitudes and opinions of the target groups are crucial in order to determine the success of policy implementation (Monjane, 2009, p.1). One of the most important ways the study attempted to understand language needs at schools was assessing parents' language needs for their children. The main purpose of the study was to assess the parents' multi-language needs for their children to learn at elementary schooling framing on those languages articulated in the policy (Mother tongue, Tigrinya, Arabic and English) and emphasizing to mono-linguality trends resulted from sole mother tongue education. Saaho language had taken as mother tongue in this case. Fishman language use domains were used as basis of theme categorization for analysis and the suppositions had drawn to detail the parents' multilingualism needs. This study had keenly contributed as preliminary information for language policy modification at elementary education since it studies on grass root (children and their parents) needs for language learning at school. The study found that Saaho language is dominantly used in family domain, education domain, and friendship domain. In readings and writing, English was found accompanied with Saaho at school. Arabic is dominantly used at religious domain both in readings, writings, and speaking. The comparison was made between the languages used currently at school by the child with those expected (preferred) by their parents', and the study found that Tigrinya and Arabic languages were highly preferred by the parents to learn their children at schools, then Saaho and English were preferred subsequently. Considering both the original intention of language policy and the results from the study, the study recommends David Laitin " $3 \pm 1$ " solution for language learning would be fruitful if it incorporated into elementary level education curriculum.
\end{abstract}

Keywords: Multilingualism needs, Elementary education, Mother tongue Education, Language Policy, Language use Domains, Fishman, David Laitin.

DOI: $10.7176 / \mathrm{JEP} / 11-2-01$

Publication date: January $31^{\text {st }} 2020$

\section{Introduction}

In the context of education in the issues of language of choice for learning is a hotly debated agenda in the literature particularly where primary education is concerned. It trace back to the perennial debate between liberal theory and communitarian theory (Kymlicka, 1995). Kymlicka (1995), after saying that there is no contradiction between liberalism and collective rights, maintains that individual rights could only be achieved within collective rights ( $p$. 34). Indeed liberalism grants people a very wide freedom and rights of choice in terms of how they lead their lives, and what is the conception of a good life (Kymlicka, 1995, p. 80). This thought was supported further arguing that by the 'rights orientation' strand, "the language as right 'orientation' considers language as basic human rights and that every human being has the right to choose a language" (Agbedor 2009, p. 141). Let's cease the debate open, this study may not cover the whole contest in the literature, just the inference had made who decides a language for a child, the parents or the government?

In Eritrea, the government had decided the language of instruction at every level of education. The policy allows a member of an ethno linguistic group in the country to attend elementary schooling in his/her own mother tongue; English is also taught in elementary schools in preparation for English medium instruction in secondary and higher-level education (Yonas, Jeanne \& Sjaak, 2006). Ouane (2003) estimated that in Sub-Saharan Africa there are between 1, 250 and 2,100 languages; however, school children in this region very rarely have chances to receive their education in the mother tongue (cited Mebratu, 2016 p.17). Unlike other sub-Saharan countries Eritrea is among those countries provide mother tongue education for whole primary level as confirmed by Kuper adds in his report that in 22 out of 39 African countries primary education still uses one of the colonial languages; Only three countries-Ethiopia, Eritrea, and Somalia have employed mother tongue for the whole duration of primary education (Kuper, 2003 as cited in Mebratu, 2016 p.17). Indeed it has been said that Eritrea is a good example of a country actively engaged in language preservation through mother tongue education (Tekle, 2003).

The underlying rationale for providing the mother tongue education is based on the notion of equality among languages, noted that "the post-independence government of Eritrea introduced mother tongues as mediums of instruction at lower levels of education, while declaring with the principle "all languages are equal" (Negash 1999, 
Gottesman 1998, Constitution 1997)" (cited in Bereketeab, 2010 p.2). Despite justice attempt in elementary education, equality among languages for work is paradoxical; only the two languages were nominated in the country for official purposes and the policy claims the languages must be taken as subjects across entire ethnic groups as it had been said "in addition to all elementary school students are required to take Tigrinya and/or Arabic, the two languages that were considered the working languages of the government of Eritrea, and English, the European language the government has chosen for international communication and as the main medium of instruction in all Eritrean schools beyond the primary school level" (Tekle 2003, p.8). The languages stated in the policy are taking into consideration while talking about multilingualism in this study. The four languages: (The mother tongue (as child's vernacular language); Tigrinya and Arabic (as working languages); and English (as the International language). However, in the last 26 years only the mother tongue aspect of the policy had implemented successfully. The more focus had been given to mother tongue, but the government should have been given parallel focus to the common languages though it is ongoing process as the its original intention for multi-language learning, instead of children learning only mother tongue, they could learn additional languages, if it had been applied successfully.

The effect of sole mother tongue education given for the children tends to shape them as monolinguals especially in rural areas. The research revealed that there are several children and women are still wholly monolingual in rural areas (Ministry of Education, 2007). Thus, mono-linguality is pervasive across different ethnic groups in the country. It is common to see lots of people who speak only Tigrinya or only Saho, only Tigre, only Arabic, only Afar and so on. The same problem applies to all places and ethnic groups in the country in which little influence of other languages appear. It is obvious that if children learn by their mother tongue in rural areas that did not get access of learning other languages; they remain with one language which might or might not be supportive to them out of the locality. This should not be happened to the African norm-for multilingualism noting that multilingualism is a fact of African life; multilingualism is Africa's lingua franca (Richard \& Graham, 2003 p.3).

For an illustration, the recent study done by (Desta \& Anthony, 2006) on "how mother tongue language policy affects pupils and their access to information in Eritrea" clearly addresses the setbacks of sole mother tongue education given for the children at elementary level especially for those children whose mother tongue are different from the working languages which are nominated for official communication, and the study found that there is little opportunity to apply the knowledge acquired via one of Eritrea's minority mother tongues in official work, except in the teaching profession. For practical purposes Tigrinya and Arabic are the work languages. They are used in meetings and when writing official documents. People from minority groups who do not have a good command of either language are dependent on others. Minorities study through the medium of their mother tongue and, if they progress further, through English; these are not working languages (p. 9). Chefena (1996) suggested that educational language policy should take into consideration a learner's advantage in terms of access to resources, jobs, upward mobility, and science and technology (cited at Desta \& Anthony, 2006, p.9 ).

The policy was clear since its inception stating that every nationality has the right to its own language or any other language of its choice at the primary school (Provisional Government of Eritrea, 1991, n.p). Little information has understood about Saaho-speaking parents' language needs for their children at elementary education in Eritrea, though multilingualism need has already confirmed by the previous study (Romadan, 2015, p.58) involving seventeen participants (17) for interview from Senafe sub-region found that in a place called Golo around Senafe, some students and their parents were asking teachers claiming that they need to learn other languages. Since the old times Les Gottesman's studies in Eritrea show that some communities expressed preference of different medium of instruction than their own mother tongue: Sometimes instead of using their mother tongue, in some areas they prefer some other language, they prefer Tigrinya, or they prefer Arabic because they think that since these two languages are more widely used in many parts of Eritrea and everybody knows this language so our children could benefit t more from this, and so on (Gottesman 1998, p. 226). What is not clear is that what language/s is required and what language/s is relevant for the child to learn at elementary schooling. The main purpose of this study is to gain understanding of educational language needs of Saaho-speaking parents for their children from specified languages mentioned in the policy. To shed light on ambiguities like which language/s are parents choose and why, which actually can be basic preliminary information for policy modification at elementary level education.

The study has rooted upon Fishman language domains theory to base its analysis. The early theory which addresses human interactional behavior in bilingual/multilingual setting (Fishman 1965; Fishman 1971; Fishman 1972a; Fishman 1972b) (cited Marie Rydenvald, 2018 p.7). Fishman refers to the five essential domains; family, friendship, religion, education, and work, and these domains are "commonly associated with a particular variety or language" (Fishman 1972a) (Marie Rydenvald, 2018, p.7). Domains are often referred to as either formal, e.g. religion and work, or informal, e.g. family and friendship (et.al). Fishman (1965) attests that the concept of domains of language choice represents an attempt to provide socio-cultural organization and socio-cultural context for considerations of variance in language choice in multilingual settings. Fishman (1965), when studying the 
social institutions and language variety, he remarks the topic of conversation and language use domains; the main agenda of language is not the language itself rather the language choice and use determined, by who, when, what to whom. Fishman clarifies using in his example; two individuals who obviously prefer to speak to each other in $\mathrm{X}$ nevertheless switch to $\mathrm{Y}$ (or vacillate more noticeably between $\mathrm{X}$ and $\mathrm{Y}$ ) when discussing certain topics leads us to consider topic per se as a regulator of language use in multilingual settings (Fishman, 1965, p.6). The theoretical relevance of the theory to this study has not only seen important for understanding the language use in multilingual setting, but also it facilitates understanding on various domains by which the language use in one domain is affected by other domains. From this connotation, it was presumed that the parents' a particular language/s choice for their child in education can be affected by other domains what he describes "language behavior" is dictated by certain social domains (Fishman, 1965). He concluded that habitual language choice is far from being a random matter of momentary inclination; even under those circumstances when very well function as such from a purely probabilistic of view (p.1). it has been said also 'Language is a social notion; it cannot be defined without reference to its speakers and the context of its use' (Wei, 2000) (as cited Monica, 2019, p.2).

There are two central objectives of this study. 1. To assess current languages used by children using domains from Fishman language domains theory, this actually helps to lead to the second objective to compare what languages are parents looking for in elementary education, as Fishman tells the domains are so interconnected, a language used in a particular domain can be affected by the relative importance of that language in another domain (Fishman, 1965). 2. To investigate the parents' language needs for their children to learn at elementary education, and compare with the languages already known by objective one. The following research questions were answered throughout the study:

1. What language/s do children currently using in relation to Language Domains?

2. Which language/s do parents opt for their Children to learn at elementary level education, and why?

3. What are the implications to educational language policy decision regarding the parents' expectation?

\subsection{Conceptual Framework}

Fig.1

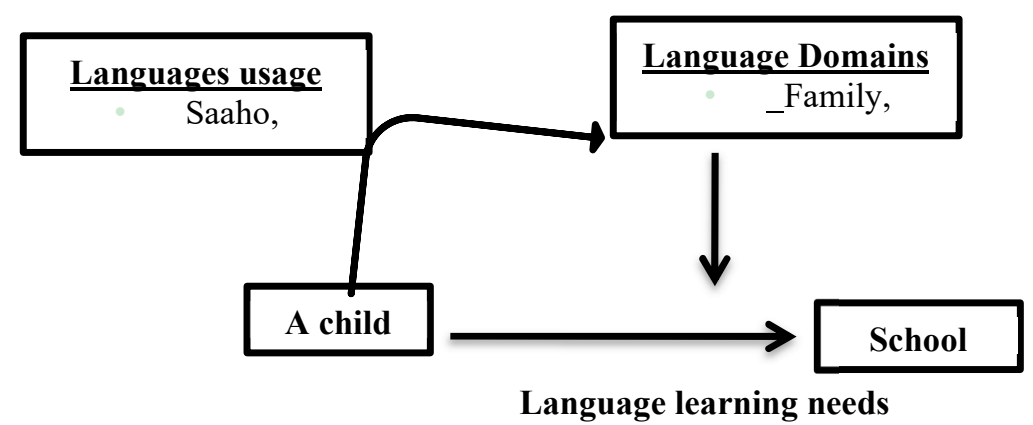

The conceptual frame work for this study has clearly depicts the relationship of the variables hypothesized standing from on the Fishman language suppositions. The underlying assumption is that the usage and importance of a particular language/s in a particular domain can be affected by its relative usage and importance in other domains. From this connotation, it has been conceptualized that the language/s learning preferences at schools might be affected by its usage in other domains. If the languages are valuable for a child in a family, religion, work and friendship other than in the school, the child would be motivated to learn that languages at school, and in this study the parents language expectation (preference) for their children to learn at school had assumed to be influenced by relative use of the language/s among the domains. Responding to such in a complex situation, the same phenomenon was raised and given solution by David Laitin (1992), who is one of anthropological language specialists who significantly had contributed to the language discourses on African languages use rationalization. He thought that there are macro forces that require international and national communication; on the other hand, there is a micro dynamics of language use which is reflected in the individual's language repertoire. On the whole, he advised solution on the language use problems in African Countries to adhere $3 \pm 1$ formula in their language planning in education. As it has been noted (Richard \& Graham, 2003), he suggested that:

The outcome of language rationalization in African states is liable to converge in most countries on a $3 \pm 1$ formula, which is to say that individual language repertoires will be required to include competence in between two and four languages. The three most commonly occurring languages will be 1) a language of wider communication for official and international purposes, which will commonly be a European language, 2) an African lingua franca (standardized from an indigenous language, pidgin or Creole), 3) a regional vernacular. Where individuals are socialized in one of the larger languages that is nevertheless not the regional vernacular, they will need to acquire four languages; however, an individual who is socialized in an African lingua franca, which is also a local vernacular, will need to learn only two 


$$
\text { languages (p.11). }
$$

\subsection{Method and Instrument}

Depending on purpose the study, qualitative method become an alternative to uncover parents' opinions on their children language needs. The qualitative method has helped a researcher to uncover details by letting parents to express their expectations. The flexible character of qualitative research makes it additionally capable for an exploratory investigation of new concepts (Bryman 2004 n.p). The study has employed a semi-structured interview to approach parents; semi-structured interview, as an approach to 'enter into the other person's perspective' (Patton, 2015, p. 426). The questions were pre-organized under the Fishman's language domains (Family, Friendship, Religion, Education, and Work). Justification of using these domains has been explained in the previous section; only the work-domain was intentionally exempted when assessing the child's current-language/s usage since it is not applicable for them as they are still little children far from work-place context. The question items were taken from "language-census items" used Joshua A. Fishman (1969) work A Sociolinguistic Census of a Bilingual Neighborhood. He used for neighborhood household study to English and Spanish languages. In this study three more languages were assessed on top of an English language (Saaho, Tigrinya and Arabic), but still relevant to use it, since the aim of both study is quite similar.

Some question items were modified according to the context preserving the item-constructs used by Fishman to retain the validity of the questions. The wording for constructs was preferred to keep as it is; only multiplying the number of items was done as the study deals with the four languages. Totally fifteen (15) items were produced, translated and discussed. The three features of language literacy (Speaking, Writing and Reading) were taken as the benchmarks in each question items to assess the language use as used by Fishman (1969) in his work to assess the variety of language behavior in different context. Face to face interview based questionnaire completion was carried out by the researcher himself, as it has been told possible "questionnaires and tests may be administered in an interview face-to-face situation" (Robson \& McCartan, 2016 p. 241). The questions were asked to 30 parents orally by translating into local language (Saaho), and their responses were written by the researcher himself by coding the number of occurrences under each language in every domain. The researcher ticks and/or some occasions circling the response forwarded by parent, because the parents are neither can speak nor to write in English correctly. The parents were invited to a tea shop to enable open-conversation, interviews as conversation (Denzin 2001). The parents were given a chance to elaborate their opinions on justifications of their need as the objective is to investigate their expectations on child education-language. The researcher wrote all said by the parents in local language since it become an alternative to quote as it is what has been said. Having face-to-face meeting with them, it boost up the conversation by observing overt reactions and inferring covert feelings during the meeting. Fishman supported face-to-face chat in his language investigation saying that to understand the language choice and topic, appropriate may be for analyses of individual behavior at the level of face-to-face verbal encounter (Fishman 1965, p.8)". Then the translation was re-translated from Saaho into English, and double checked by Saaho-speaking teacher who has long years of experience in teaching English subject at secondary level to ensure reliable-translation.

\subsection{Sampling Strategy and Sample Size}

The study included 30 parents from the two villages in rural area in Senafe sub-region. The villages are Golo and Merber found. The villages were purposively chosen as the population is Saaho-speaking population, and have elementary schools. Besides, the site had chosen because there was one study remarks for multilingualism need in those areas (Romadan, 2015). The convenience sampling was used to make conversation with those parents who can easily be accessible by the researcher. Fifteen (15) parents from each village were taken. The following table shows demographic details of the participants:

Table1. Demographic information of Participants

\begin{tabular}{l|c|c|c|c|c|c} 
& Gender & \multicolumn{2}{|c|}{ Level of Education } & \multicolumn{3}{c}{ Current Occupation } \\
\hline \hline Men & Women & No formal Education & Basic Education & Farmer & Teacher & House-wife \\
\hline 19 & 11 & 26 & 4 & 18 & 2 & 10 \\
\hline
\end{tabular}

As Table 1 represents most of the participants were men, and have no formal education. However, for the sake of information they are right persons to tell their expectation on their children language education, as this level of education has no doubt in this study. for their occupation, most of the participants do farming, and housework for women, and two are teachers who are currently teaching at elementary schools nearby the village.

\subsection{Data Analysis}

Coding and thematic analysis (Braun \& Clarke, 2006; Coffey \& Atkinson, 1996) were used to analyze the interview data. The responses were analyzed under each theme (domain) of Fishman language theory that previously has been used in designing questions, but contextually the more focus has given in education domain, 
and the scope of education domain has limited only to elementary education. Initially, the responses were coded by the researcher and then re-coded by English teacher. The number of occurrences for languages was coded from 1 to 4 on 15 question items for 30 participants (parents). Totally it was coded 450 times by the researcher and the English teacher as mentioned before. Inter-rater reliability was computed to see the level of agreement among coders, and the Kappa value of 1 was gained which actually indicates strong reliable coding. To examine language/s used in different domains the frequency table was used using SPSS, and Cross-tabulation was done to compute differences between the languages currently used at school with those language/s expected (preferred). The first research question has answered on table 2 to table 5, and the second research question has answered on table 6 to table 9 with one probing question, and through the expression of their expectations, an implication was made to answer research question 3 .

\subsection{Results}

Table2. The Languages Used by a Child at Home (Family Domain)

\begin{tabular}{cl|c|c|c|c|c|c}
\hline \hline \multicolumn{2}{l}{ Mostly Read at home } & \multicolumn{3}{l}{ Mostly Written at home } & \multicolumn{2}{c}{ Mostly Spoken at home } \\
\hline \hline \multirow{5}{*}{ Languages } & Frequency & Percent & Frequency & Percent & Frequency & Percent \\
\hline & Saaho & 19 & 63.3 & 16 & 53.3 & 27 & 90 \\
\cline { 2 - 9 } & Tigrinya & 3 & 10 & 3 & 10 & 1 & 3.3 \\
\cline { 2 - 9 } & Arabic & 6 & 20 & 10 & 33.3 & 2 & 6.7 \\
\cline { 2 - 9 } & English & 2 & 6.7 & 1 & 3.3 & 0 & 0 \\
\cline { 2 - 9 } & Total & 30 & 100 & 30 & 100 & 30 & 100 \\
\hline \hline
\end{tabular}

As it has shown Table 2, Saaho language is the mostly used language at home among the languages mentioned on the table; for reading (63 percent), for written ( 53 percent), and for spoken ( 90 percent). Indeed, Arabic language usage in readings and writings is quite notable as shows 20 percent and 33 percent respectively.

Table3. The Language Used by a child at Mosque (Religion Domain)

\begin{tabular}{|c|c|c|c|c|c|c|c|}
\hline \multicolumn{3}{|c|}{ Mostly Read at Mosque } & \multicolumn{3}{|c|}{ Mostly Written at Mosque } & \multicolumn{2}{|c|}{ Mostly Spoken at Mosque } \\
\hline & & Frequency & Percent & Frequency & Percent & Frequency & Percent \\
\hline \multirow{3}{*}{ Languages } & Saaho & 4 & 13.3 & 1 & 3.3 & 15 & 50 \\
\hline & Arabic & 26 & 86.7 & 29 & 96.7 & 15 & 50 \\
\hline & Total & 30 & 100 & 30 & 100 & 30 & 100 \\
\hline
\end{tabular}

Table 3 illustrates only two languages Saaho and Arabic languages are used by the child in mosque. Arabic has the highest score in readings and writing in Mosque as displayed on the table 86 percent and 96 percent respectively. However, equal score has registered in speaking between the two languages at Mosque.

Table 4. The Languages Used by a child at School (Education Domain)

\begin{tabular}{l|l|c|c|c|c|c|c}
\hline \hline \multicolumn{2}{l|}{ Mostly Read at School } & \multicolumn{3}{c|}{ Mostly Written at School } & \multicolumn{2}{c}{ Mostly Spoken at School } \\
\hline \hline \multirow{3}{*}{ Languages } & Frequency & Percent & Frequency & Percent & Frequency & Percent \\
\hline & Saaho & 25 & 83.3 & 18 & 60 & 26 & 87 \\
\cline { 2 - 8 } & English & 5 & 16.7 & 12 & 40 & 4 & 13 \\
\cline { 2 - 9 } & Total & 30 & 100 & 30 & 100 & 30 & 100 \\
\hline \hline
\end{tabular}

As table 4 depicts, Saaho and English are the only two languages used in school, and Saaho is the most used language at school by the child. The English score has quite approachable in writing maybe because, English has given as subject from grade one up to grade five according to the policy.

Table 5. The Languages Used by A Child with Friends (Friendship Domain)

\begin{tabular}{cl|c|c|c|c|c|c}
\hline \hline & \multicolumn{2}{l}{ Mostly Read with Friends } & \multicolumn{2}{c|}{ Mostly Written with Friends } & \multicolumn{2}{c}{ Mostly Spoken with Friends } \\
\hline \hline \multirow{5}{*}{ Languages } & Frequency & Percent & Frequency & Percent & Frequency & Percent \\
\hline & Saaho & 24 & 80 & 20 & 66.7 & 27 & 90 \\
\cline { 2 - 9 } & Tigrinya & 2 & 6.7 & 1 & 3.3 & 3 & 10 \\
\cline { 2 - 9 } & Arabic & 4 & 13.3 & 9 & 30 & 0 & 0 \\
\cline { 2 - 8 } & Total & 30 & 100 & 30 & 100 & 30 & 100 \\
\hline \hline
\end{tabular}

In a friendship domain Saaho takes the highest among Tigrinya and Arabic in friends' conversation. It is mostly used language by the child with friends, though 30 percent of the respondents said they use Arabic mostly in writing being together or with each other. 
Table 6. The Languages Used for readings at School and the Languages Preferred

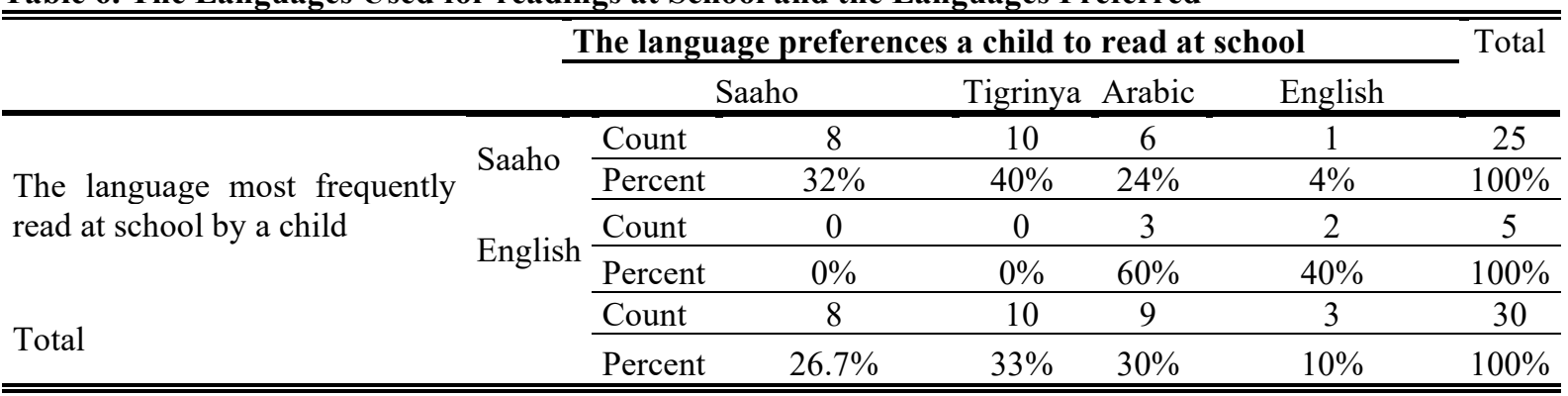

Pearson Chi-square sig: 0.01

To see the variance between the language/s currently read by the child at school and the languages preferred to read at school from the parents' perspective, cross-tabulation has used, and found that it is significantly different as $\mathrm{P}$ value is 0.01 in 0.05 cutting point was used for level of significance. Saaho is mostly used language by the child but it ranks second in the language preference. Tigrinya and Arabic are the highly preferred languages to be used in readings at school.

Table 7. The Languages Used for Writing at School and the Languages Preferred

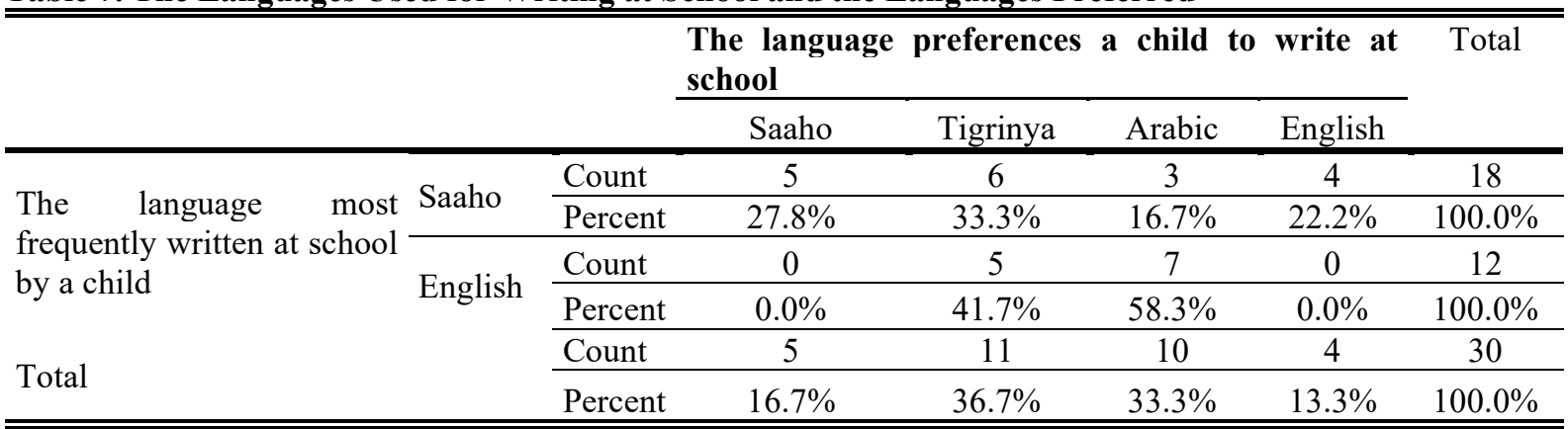

Pearson Chi-square sig: 0.02

The same as table 6 , table 7 computes the languages used in writing at school with the languages preferred, and found that the languages currently used for writing at school is significantly different from what parents' had preferred for their children to write at school by 0.02 significance value. A child uses mostly Saaho for writings at school, but ranked third according to the response. Parents' prefer first Tigrinya (36.7 percent), and second, Arabic (33.3 percent), and English preferred least (13.3 percent).

Table 8. The Languages used for speaking at School and the Languages Preferred

\begin{tabular}{|c|c|c|c|c|c|c|c|}
\hline & & & \multicolumn{4}{|c|}{$\begin{array}{l}\text { The language preference a child to speak at } \\
\text { school }\end{array}$} & \multirow[t]{2}{*}{ Total } \\
\hline & & & Saaho & Tigrinya & Arabic & English & \\
\hline \multirow{4}{*}{$\begin{array}{l}\text { The language mostly spoken } \\
\text { at school by a child }\end{array}$} & \multirow{2}{*}{ Saaho } & Count & 4 & 9 & 8 & 5 & 26 \\
\hline & & Percent & $15.4 \%$ & $34.6 \%$ & $30.8 \%$ & $19.2 \%$ & $100.0 \%$ \\
\hline & \multirow{2}{*}{ English } & Count & 4 & 0 & 0 & 0 & 4 \\
\hline & & Percent & $100.0 \%$ & $0.0 \%$ & $0.0 \%$ & $0.0 \%$ & $100.0 \%$ \\
\hline \multirow{2}{*}{ Total } & & Count & 8 & 9 & 8 & 5 & 30 \\
\hline & & Percent & $26.7 \%$ & $30.0 \%$ & $26.7 \%$ & $16.7 \%$ & $100.0 \%$ \\
\hline
\end{tabular}

Pearson Chi-square sig: 0.005

The languages spoken at school by the child is significantly different from what parents' prefer their child to speak at school with significance value of 0.005 . Saaho is dominantly spoken language at school, but Tigrinya is highly preferred by parents. 
Table 9. Languages used at School and the Languages Preferred

\begin{tabular}{|c|c|c|c|c|c|c|c|}
\hline & & & \multicolumn{4}{|c|}{ Preferred languages to use at school } & \multirow[t]{2}{*}{ Total } \\
\hline & & & Saaho & Tigrinya & Arabic & English & \\
\hline \multirow{4}{*}{$\begin{array}{l}\text { Child Used Languages at } \\
\text { school }\end{array}$} & \multirow{2}{*}{ Saaho } & Count & 52 & 66 & 59 & 30 & 207 \\
\hline & & Percentage & $25.1 \%$ & $31.9 \%$ & $28.5 \%$ & $14.5 \%$ & \\
\hline & \multirow{3}{*}{ English } & Count & 14 & 21 & 22 & 6 & 63 \\
\hline & & Percentage & $22.2 \%$ & $33.3 \%$ & $34.9 \%$ & $9.5 \%$ & \\
\hline Total & & Count & 66 & 87 & 81 & 36 & 270 \\
\hline
\end{tabular}

In a nutshell, the overall languages currently used at school (for reading, writing and for speaking) have crosstabulated with the corresponding languages which are preferred to use at school. Based on the responses as shown on the table 9, Saaho is using at school with the highest responses rate of (207), and Tigrinya has highly preferred with response rate of (87). Saaho has preferred after Arabic as the response rate shows (66) and (81) respectively.

\subsubsection{Qualitative Responses}

The qualitative responses are summarized into main remarked points identifying the main descriptions among the parents accompanying with their quantitative results. The parents' standing to justify their decision for language choice has descriptively narrated, and the common response was taken to represent with the same argumenters. Those parents who are fancy of using Saaho at elementary education (66 response rates out of 270 responses, see on the table 9) defend their argument, for example one the parents view has noted. He articulated informative expressions in his statement:

Saaho is our language....Saaho is our culture. I am happy elementary schooling is by Saaho, we must teach our language and should inherit our unique culture. "Ishim isheh ciddemko mari kum maaba" literally meaning that "nobody will collect yours' if you throw by yourself".

However, most of the interviewed parents preferred Tigrinya for their children to learn at elementary education with 207 responses rate (see table 9). One of the interviewed parents remarks the following statements: I have many charts in my house containing Tigrinya alphabets and words. I need my children to master Tigrinya language. Because as the end of the day they will be out of the family, or village for work.........nearly most of the people found there might not speak Saaho, and almost all the offices they need Tigrinya

Those of parents proponed for Arabic, proposed as follows;

The kuran has revealed in Arabic....is our guide book on this earth. I need every one of my children must able to recite it and know meaning of it. Not only that if you are able to speak Arabic, you have priority to be selected for the job. If you move outside the country, to Soudi-Arabia and if you cannot speak Arabic you would not get jobs....it helps a lot.

Finally, the parents were asked to express their expectation on schools teaching multi-languages, and most of the parents said that they need schools to teach children with different languages in addition to Saaho language.

\subsection{Discussion}

The study has assessed the languages used by children earthier for readings, writing, and speaking, using language domains. The elementary education policy was taken as a frame to identify four languages that became pertinent for study: Saaho, Tigrinya, Arabic, and English. The study has carried out by with two objectives to achieve its purpose. First, child language/s usage was assessed from the above mentioned languages using Fishman language domains. This was done intentionally because; the languages used in schools must be relevant with the social sphere of the child, and Fishman assumes that a particular language used in a particular domain can be affected by its importance in other domains (Fishman, 1969), and David also suggests that micro dynamics like individual repertoires and macro dynamics like national and international demands compel individuals to use multi-languages (David, 1992). The inference has made that the languages might be used at schools would be affected by other domains or factors. Second, parents' expectation through their preference was investigated on the languages to be used at schools.

The result shows that Saaho is the most used language among other three languages in family domain, education domain and friendship domain. This could be attributed to the population living that areas is dominantly Saaho speaker but in mosque Arabic is dominant. This might be because as it has been said every Saho individual and child from his early age has to recite the Quran in Arabic; in most cases, even families prefer to send their children to learn the holy Quran before he starts the secular education; this has contributed to their familiarity and relative ability to speak, and read as well as write the Arabic language and venerate it as a religious language as well. Besides Arabic language accentuates important part in the daily life of the Saho community; marriage agreements, property inheritance, genealogy, conflict resolutions are all documented in the Arabic language. Because of these facts, almost every adult among the Saho can read, understand and speak (if not perfectly at all) Arabic language (Romadan, 2015, p.62). The usage of English language has accompanied with Saaho at schools. 
This is because English has given as subject from grade one. But, here I want to clarify that even though English has been given from grade one as a subject, its significance can only be seen after grade six for medium of instruction; it is not used for communication.

The significant discrepancies were found among languages used at schools and to be used at schools, preferred languages that are expected by parents were different from currently used languages with 0.01 significance level. For reading $0.01,0.02$ for writing, and 0.005 for speaking was obtained indicating variance on language usage at schools. At present, only two languages are using at schools Saaho (mother tongue) is used as medium of instruction and English as subject and those parents who were satisfied about Saaho language usage at school are in tune with the policy articulating that all national groups of Eritrea have the right to develop their languages in a way which encourages the development of a new revolutionary Eritrean culture (cited Bereketeab 2010). It coincides also with UNESCO (2001) "it is increasingly obvious that the language of instruction at the beginning of one's education at such a crucial moment for future learning should be the mother tongue" (p.6).

However, most of the parents were preferred Tigrinya and Arabic for their children to learn at school (see table 9). Their main argument implies for instrumentalism purpose just for communication and employment needs as it has been confirmed that Tigrigna language became attractive as the only means of success both to the Saho students and parents; the need emanates from their desperate interest to equip themselves and their children with Tigrigna to access the essential services, thus inclusion of Tigrigna as a subject in the curriculum was the result of relentless pleading from parents and students (Romadan, 2015, p.58). The findings also corroborate with the idea of Tekle (2003) suggested that in many cases, resistance to the policy of use of the mother tongue in Eritrean schools has to do more with seeking direct economic and political rewards and benefits from learning regional and international languages such as Arabic and English. In fact, one can make a compelling argument that other than Tigrinya and Arabic, which have been designated as working languages, there is hardly any material benefit attached to being literate in the other Eritrean languages. Since English, Tigrinya, and Arabic are widely used in official communication, a person knowing all or a combination of these languages has an advantage in gaining economic and political opportunities and rewards in the modern sector of Eritrean society; thus, learning Tigrinya, English, and Arabic are advantageous in the job market as well as in governmental and international transactions (Tekle, 2003, p.17). There is little opportunity to apply the knowledge acquired via one of Eritrea's minority mother tongues in official work, except in the teaching profession. For practical purposes Tigrinya and Arabic are the work languages (Desta \& Anthony, 2006 n.p). Bereketeab, (2010) states that "... parents are aiming, by choosing a language they perceived is more marketable than their own, at the linguistic market where competitive and profitable legitimate linguistic competence is earned (p. 22).

An implication of the findings from this study is the potential for understanding elementary education language policy weaknesses. Despite its multi-language mentioning, it was not succeeded as its original intention. In the past 26 years only Saaho (mother tongue) had been implemented successfully, however, it should have been accompanying with national languages which have been nominated as common languages for all citizens. The criticisms had revolved around sole mother tongue education that inherently shapes children as monolinguals. Perhaps too many hours of language instruction is the most tangible criticisms directed at the mother tongue elementary education in Eritrea (UNESCO, 2000) (cited Yonas, Jeanne \& Sjaak, 2006, p.2). However, mother tongue cannot be criticized by itself as it has a lot of benefits for the child but the failure comes to linkages with other language group. If the common languages had been given for all ethnic groups, and then it might resolve the language barriers and maintain multi-lingualism among students. The study has in tune with Laitin assertion to promote multi-lingulism in elementary schools, and the policy makers must keenly reconsider it. In general, it had been also suggested well by Richard and Graham (2003) that to reconcile top-down and bottom-up perspectives on Africa's language problem, Laitin's argument deserves the attention of all policy makers who wish to ease the pain of transition to an outcome he feels is inevitable (p. 20). To satisfy multilingualism needs at elementary schooling, the researcher strongly believe on David Laitin " $3 \pm 1$ " solution for language learning would be helpful in elementary schooling in Eritrea. According Laitin (cited Tekle, 2003, p.19) states that if the person's vernacular is the same with the lingua franca, then the person will need to learn only two (3-1) languages, and if the person's vernacular is different from the language taught in the region's primary schools, the citizen has to learn four $(3+$ 1) languages (Laitin 1992, 1994; Fardon \& Furnish 1994).

Indeed, the relevance of Laitin formula in Eritrea elementary education had already recommended by earlier the study that in Eritrea, " $3 \pm 1$ "outcome would give all Eritreans the ability to communicate effectively with each other and with most of the rest of the world (Tekle, 2003, p.19). There might be a people skeptical about the inability of children learning more than one language, but studies argued contrarily; for example, on July 14, 1997, South Africa implemented a Language in Education Policy, stipulating that schools were required to recognize all of the 11 national languages. That is, students could decide their language of instruction, and the government had to make accommodations for all students. Within the policy document, the Department of Education declares, "This approach is in line with the fact that both societal and individual multilingualism are the global norm today, especially on the African continent, as such, it assumes that the learning of more than one language should be a 
general practice and principle in our society" (DOE, 1997, p. 1) (Cited by Francisco O. et al., 2017 p.28).

For further investigation, the study leaves open for researchers to investigate deeply the difficulties intervening in the policy implementation at elementary education so that more information would clear. In order to succeed in this issue, policy makers' perspective must be earned as this study had focused on from users' (parents) perspective only.

\section{Conclusion}

This study argued that language needs of parents for their children are important in determining language needs of the children at school. As Baker (2006: 210) correctly puts it, 'a survey of attitudes' works as a mirror of a 'community's thoughts, beliefs, preferences and desires' and will provide us with an indication of the likelihood of 'success of any policy implementation The first teachers for the child is his parents, they have right to be share their expectations on the languages given at school. Throughout the responses, Saaho and English languages have repeated several times. As it was planned in the policy, the languages required for common communication and employment should have been given for children at school. As it has shown on table 9, the most responses were given Tigrinya and Arabic, the languages entitled official languages of Eritrea, Arabic and Tigrinya shall be employed in all activities (Bereketeab 2010 n.p). The parents' preference is not barely founded rather tangible evidences are scouted their justification, learning Arabic and English opens up opportunities for employment outside of Eritrea (Tekle, 2003, p.17). The concerns have clearly mentioned that learning only by mother tongue (Saaho) language cannot be sufficient to help children out of locality, even though English is given as subject from grade one, it's function has not seen before grade six, as it become medium of instruction. Language policy needs to be flexible to address the concerns. Sole mother tongue education without linkage to common languages might encourage dis-unity among ethnics which is contrary with initial goal. The goal of languages policy in education had been noted (Bereketeab, 2010, p. 35) Eritrean Government, described their education and language policy as intended to promote national unity and development (cf. National Charter 1994, Constitution 1997). It is true to note that the policy discussions of language need to attain an appearance of objectivity, and the globally available rhetorics to achieve this include the discourses of human rights, economic utility and governmental efficiency, as well as aesthetic expression and the authenticity of personal and collective identities (Richard \& Graham p.11).

\section{Acknowledgement}

I would like to thank Professor Xia Xue and Professor Zhu Hong providing constructive feedbacks and comments on earlier version of this article. I am also grateful to thank all participants providing substantial information for this research.

\section{Declaration Statement}

The author declared no potential conflicts of interest with respect to the research, authorship, and/or publication of this article.

\section{References}

Agbedor, P. (2009). The Language Factor in West Africa's Integration: Nation-Building and the Challenges of Regional Integration in West Africa, the case of Ghana, Kwame A. Ninsin (ed). Paris: Karthala.

Baker, Colin (2006). Foundations of Bilingual Education and Bilingualism. Clevedon: Multilingual Matters

Bereketeab, R. (2010). The Politics of Language in Eritrea: Equality of Languages vs. Bilingual Official Language Policy, African and Asian Studies, 9, (1-2), p.149-190.

Braun, V., Clarke, V. (2006). Using thematic analysis in psychology. Qualitative Research in Psychology 3: $77-$ 101.

Bryman, A. (2004). Qualitative research on leadership: A critical but appreciative review. The Leadership Quarterly, 15, 729-769. doi:10.1016/j.leaqua.2004.09.007.

Coffey, A., Atkinson, P. (1996). Making Sense of Qualitative Data: Complementary Research Strategies. Thousand Oaks, CA: SAGE Publications.

Denzin, N. K. (2001). Interpretive interactionism. London. Sage.

Desta.B., Anthony, O. (2006). Elementary Education in Eritrea: How Mother Tongue Language Policy Affects Pupils and Their Access to Information, doi: 10.1177/095574900601800204, https://www.researchgate.net/publication/300103662.

Fishman, J., A. (1965). Who speaks what language to whom and when?. La Linguistique, Vol. 1, Fasc.2 pp. 6788, Presses Universitaires de France.

Fishman, J.A. (1969). A Sociolinguistic Census of a Bilingual Neighborhood, American Journal of Sociology, 75(3), pp. 323-339, University of Chicago Press. URL: https://www.jstor.org/stable/2775695

Francisco O. R., Patricia B., \& Susan, G. R. (2017).The valorization of humanity and diversity. In C. Y.-K. Cha et al. (eds.), Multicultural Education in Global Perspectives (pp.28-34). Singapore, Springer Nature. 
Gottesman, L. (1998). To Fight and Learn: The Praxis and Promise of Literacy in Eritrea's Independence War. Trenton NJ: Red Sea Press.

Kuper, W. (2003). The necessity of introducing mother tongues in education systems of developing countries. In Ouane (Ed.), Towards a Multilingual Culture of Education, 89-102. Hamburg: UNESCO Institute of Education.

Kymlicka, W. (1995). Multicultural Citizenship: A liberal theory of minority rights. Oxford: Clarendon Press

Laitin, D.D. (1992). Language Repertoires and State Construction in Africa, Cambridge: Cambridge University Press (Cambridge studies in comparative politics).

Marie, R. (2018). Who speaks what language to whom and when: rethinking language use in the context of European Schools, De Gruyter Mouton, https://doi.org/10.1515/ijsl-2018- 0034.

Mebratu, B. (2016). Mother Tongue as Medium of Instruction: Benefits and Challenges International Journal of Innovative Language, Literature \& Art Studies 4(1):16-26.

Ministry of Education, (2007). Basic education statistics 2006/07. Asmara. Eritrea.

Monica, A. (2019). Multilingualism at church: language practices in a Ghanaian context, Current Issues in Language Planning, doi: 10.1080/14664208.2019.1582946, 20 (4), p. 403-417.

Monjane, S., H. (2009). Children and Parents' Perceptions on the languages in use in a rural school context in Mozambique, Phd theses Universidade Pedagógica, Mozambique

Patton, MQ (2015). Qualitative Research \& Evaluation Methods: Integrating Theory and Practice. Thousand Oaks, CA: SAGE Publications.

Provisional Government of Eritrea, (1991). "Declaration of Policies on Education in Eritrea." Legal Notice, Number 2-1991 (Oct. 2), Department of Education, Asmara, Eritrea.

Richard, F., \& Graham, F. (Eds.). (2003). African Languages, Development and the State: New edition published in New York, London, Taylor \& Francis e-Library, ISBN 0-415-09476- (Print Edition)

Robson, C., \& McCartan, K.(2016). Real World Research: A Resource for Users of Social Research Methods in Applied Settings, (John Wiley \& Sons Ltd) Fourth Edition, Trento. Italy: ISBN: 9781118745236.

Romodan A. (2015). 'Thesis in Peace and Conflict Transformation', the Question of Structural Violence on the Saho people of Eritrea, in spite of their important role during the Eritrean Struggle for Independence: University of Tromso, Norway.

Tekle, M. (2003). Language, Education, and Public Policy in Eritrea. African Studies Review. AfricanStudiesAssociation,46(1). pp.117-136,URL: http://www.jstor.org/stable/1514983.

UNESCO (2001). Universal Declaration on Cultural Diversity; Action Plan, Paragraph 8. Paris, UNESCO.

Yonas, M., Jeanne, K., Sjaak, K. (2006). Literacy use and Instruction In Multilingual Eritrea, AfricanStudiesBulletin68,pp. 70-78. URL: http:/lucas.leeds.ac.uk/article/literacy use-nd-instruction-in multilingual-eritrea-yonas-mesfun-asfaha-jeanne-kurvers sjaak-kroon. 